\title{
Restart of Hospitality and Tourism: System Dynamics and Scenario-Based Modelling
}

\author{
Petr Štumpf \\ Prague University of Economics and Business \\ petr.stumpf@vse.cz \\ Jitka Mattyašovská \\ Prague University of Economics and Business \\ jitka.mattyasovska@seznam.cz
}

Adriana Krištůfková

Prague University of Economics and Business

kriao2@vse.cz

A tourism destination is defined as an open, complex, and adaptive system, in which numerous relations in the economic, social, and environmental spheres are generated. This paper aims to define a system dynamics model of tourism destination as a complex system and to identify future behaviour of the system after the restart of tourism in the post-COVID-19 era. The main methodological approaches were system dynamics and simulation modelling. The case of a complex tourism system in the South Bohemia Region, the Czech Republic, in the form of a Stocks and Flows Diagram (SFD) is presented in this paper, focusing on the business activities at this tourism destination. The simulation results show the future behaviours of the system in various scenarios and compare the development of several economic indicators. Three possible future scenarios of a restart of the hospitality and tourism industry are compared with the theoretical situation without CoviD-19 disease. The proposed system dynamics model contributes to the current theory of tourism destination management systems and can be used practically by destination managers for destination planning and to formulate destination strategies.

Keywords: system dynamics, simulation modelling, tourism destination, destination management

(cc)BY-SA https://doi.org/10.26493/2335-4194.14.125-136

\section{Introduction}

A tourism destination system involves a great number of stakeholders. One of the most significant stakeholders are the tourism enterprises that are regarded as a 'backbone' of the tourism destination system. A destination in which tourism enterprises operate has a significant impact on the competitiveness of these enterprises and their performance. However, the oppo- site relation also applies. It means that the competitiveness of the destination is noticeably dependent on the competitiveness of the enterprises in the destination, in terms of each individual company and all companies in aggregate (Ritchie, 2003).

The ability to compete in the tourism market is, from the perspective of individual entrepreneurs, the subject of their interest; on the other hand, the com- 
petitiveness of the whole industry and aggregated results of the private sector in the destination are important for the public administration. Thus, the competitiveness of the whole destination should be in the spotlight for destination management as represented by destination management organisation (DMO).

The hospitality and tourism industry has suffered enormously from the COVID-19 pandemic and government restrictions in all countries. The behaviour of the whole tourism system in the post-COVID-19 period is still unclear, as well.

Therefore, the main ambition of this paper is to define a system dynamics model of tourism destination as a complex system and to simulate possible scenarios of future development after the tourism system restart. We use the case of the South Bohemia Region. The South Bohemia Region represents one of the most popular tourist regions in the Czech Republic, right after the capital city of Prague and the South Moravia Region. The aim is to provide a practical tool in the form of a complex model, which could be used by destination managers to facilitate their decision making, destination planning, and destination strategies formulation in post-COVID-19 tourism development.

Therefore, we formulate the following research question: How will the hospitality and tourism industry develop in the post-COVID-19 era in the South Bohemia Region?

We use system dynamics as the main methodological approach to answer the postulated research question. A tourism destination is considered a dynamic complex system because it comprises many different components that interact in a non-linear way (Baggio \& Sainaghi, 2011; Mai \& Smith, 2018) and, therefore, it needs to be appropriately modelled to achieve efficient destination management (Bieger, 2008; Farrell \& Twining-Ward, 2004; Lew \& McKercher, 2006; Rodriguez-Diaz \& Espino-Rodriguez, 2007). System dynamics is a method to enhance learning in complex systems which often uses computer simulation models to help us learn about dynamic complexity and design more effective policies (Sterman, 200o). This method can be understood as a computer-based approach to understand and analyse a system's behaviour over time (Sedarati et al., 2019). Therefore, we use system dy- namics to simulate possible scenarios, because future tourism development in the post-COVID-19 period is still unclear and will require complex solutions.

The proposed system dynamics model contributes to the current theory of tourism destination management systems. System dynamics in travel and tourism research is used by other researchers as well (Borštnar et al., 2011; Jere Jakulin, 2016; 2017; Jere Lazanski \& Kljajic, 2006; Mai \& Smith, 2018; Patterson et al., 2004; Ropret et al., 2014; Sedarati et al., 2019; Štumpf \& Vojtko, 2016; Tegegne et al., 2018; Vojtko \& Volfová, 2015). However, the previous studies do not include such a high number of variables and interrelations and do not cover the complexity of the whole destination system as does the presented model. Only a few authors simulate future scenarios (Mai \& Smith, 2018). Thus, we see the gap in the theory and provide a scientific tool for future directions of tourism in these chaotic times.

\section{Theoretical Background}

The use of the systemic approach in tourism originates from the fact that tourism destinations are considered complex systems (Baggio \& Sainaghi, 2011; Kaspar, 1976; Laesser \& Beritelli, 2013; Mai \& Smith, 2018; Štumpf \& Vojtko, 2016). According to the SanktGallen consensus of destination management, destinations can be understood not only as geographic entities, clusters or networks of suppliers but also as productive social systems with specific business aims and non-business related goals (Laesser \& Beritelli, 2013).

\section{Tourism Destination as a Complex System}

Systems theory is used as one of the essential approaches to studying and managing the travel and tourism industry (Kaspar, 1976), especially in a specific environment of tourism destinations. Based on this theory, a tourism destination is defined as an open, complex and adaptive system, in which numerous relations in the economic, social, and environmental spheres are generated. A tourism destination is considered a dynamic complex system because it comprises many different components that interact in a non-linear way (Baggio \& Sainaghi, 2011; Mai \& Smith, 2018). The tourism destination as a complex system needs to be appropriately modelled to achieve 
efficient destination management (Bieger, 2008; Farrell \& Twining-Ward, 2004; Lew \& McKercher, 2006; Rodriguez-Diaz \& Espino-Rodriguez, 2007).

The system also contains many stakeholders with entirely different management objectives and interests (Mai \& Smith, 2018; Štumpf \& Vojtko, 2016), and it is influenced by various internal factors (such as policy, government regulations, and socio-economic conditions) as well as external factors (such as the economic situation, safety and security, and technological or environmental changes). It means that managing a tourism destination is uncertain, and destination managers have to make decisions in a complex environment (Mai \& Smith, 2018).

\section{Tourism Destination and System Dynamics}

The first system dynamics models were used for simulations in businesses (Forrester, 1961). However, system dynamics modelling enables evaluating the economic impacts and the socio-cultural and environmental impacts and their mutual interactions (Jackson, 2003). In comparison to other methods that are often used for the evaluation of the economic impact of tourism on destinations, system dynamics has one advantage - it can be operated at the same time with 'soft' factors from the social and environmental spheres, non-linear relations, delays, and causal loops (reinforcing or balancing), in one complex model (Sterman, 2000). Thus, we can observe stakeholders and general tourism development in destinations in a broader context with the emphasis on sustainability.

The system dynamics searches for an explanation of phenomena (variables within the boundaries of the system). The endogenous approach creates system dynamics through the interaction of variables and agents represented in the model. By specifying the structure of the system and the rules of interaction (decisionmaking rules in the system), it is possible to reveal behaviour patterns created on the basis of these rules and this structure, and to discover how behaviour can be changed following the alternation of the structure and rules (Sterman, 200o). For example, Jere Lazanski and Kljajic (2006) or Mai and Smith (2018) have used this approach in dynamic modelling of tourism destinations.
In contrast, the approach based on the exogenous variables (variables beyond the model boundaries) explains the dynamics of given variables in the sense of other variables whose behaviour is anticipated. An endogenous explanation of the system dynamics does not mean that the models should never contain any exogenous variables. However, the number of external inputs should not be high, and each 'exogenous input candidate' must be carefully verified. Careful consideration must be given to whether there is significant feedback from endogenous elements to the considered exogenous input in the system. If so, the boundaries of the system must be extended, and this variable must be modelled as endogenous (Sterman, 2000).

An approach based on exogenous variables has been used in tourism by, for example, Patterson et al. (2004), who deal with a dynamics system of sustainable tourism on the Caribbean island of Dominica. At first, the authors identified exogenous variables such as the global economy, politics, and climatic conditions. Only then did they outline three broad endogenous areas of research in which they identified individual variables - society (population, migration, etc.), ecosystem (land exploitations, portable capacity, etc.) and economics (GDP, income from tourism, etc.).

Several research studies have been published in the field of travel and tourism, using system dynamics as the main theoretical approach (Borštnar et al., 2011; Jere Jakulin, 2016; 2017, 2019; Jere Lazanski \& Kljajic, 2006; Mai \& Smith, 2018; Patterson et al., 2004; Ropret et al., 2014; Sedarati et al., 2019; Štumpf \& Vojtko, 2016; Tegegne et al., 2018; Vojtko \& Volfová, 2015). Moreover, Schianetz et al. (2007), based on Senge's (1990) theory of Learning Organization, present the concept of Learning Tourism Destination using system dynamics as a tool for implementing and reinforcing collective learning processes. The results show that system dynamics methodology can support communication among crucial stakeholders in tourism destinations and stimulate organisational learning.

\section{Simulation Modelling in Tourism Research}

Modelling in tourism is used mainly to understand complex systems and connections when, on the basis of the clarification of certain phenomena, it is possi- 
ble to imitate the behaviour of the investigated system, simulate it on the specific model, and then influence its behaviour. Simulation models are used in tourism, for example, to predict supply and demand, determine the impact of tourism on the economy, the local communities and the environment, to model movement of tourists in the destination, or as a tool facilitating decision-making in planning and defining development and marketing strategies (Ahlert, 2008; Andergassen et al., 2013; Athanasopoulos \& Hyndman, 2008; Bonham et al., 2009; Buchta \& Dolnicar, 2003; Greiner, 2010; Lacitignola et al., 2007; Lawson, 2006; Lew \& McKercher, 2006; Liu et al., 2012).

Nowadays, computer simulations are increasingly used in social sciences as a tool for understanding various social phenomena. Employing simulation, scientists can determine causal effects, specify key parameter estimates, and clarify the evolution of the processes over time. In addition, simulation methods are often very effective in terms of time and costs; sometimes, they are even the only possible means for examining certain phenomena (Garson, 2008). The main areas of simulations used in the social sciences are system dynamics models, network models, spatial models, and agent-based models.

Focusing on this research study, simulations grounded in system dynamics could be used to better understand the structure of the complex tourism destination system and its behaviour in a time perspective. These simulations can combine many different interrelated factors and play an important role in testing various scenarios. That is why such system dynamics simulation models can be used to make strategic decisions and for strategic planning in tourism destination development in general.

\section{Methods}

The main methodological approach was system dynamics modelling. In line with the previous studies, we built the model based on system dynamics modelling, according to the system dynamics methodology (Jackson, 2003). The first step consists of identifying a research problem and variables, which have a crucial influence on the defined problem. The variables create the boundaries of the system.

\section{The Stocks and Flows Diagram Construction} The presented system dynamics model in the form of a Stocks and Flows Diagram (SFD) shows the interactions among the defined variables and reveals the complex structure of the model. Jere Lazanski and Kljajic (2006) defined the relations among the model, the object, and the modelling subject. Based on this approach, the object of the model was defined as the dynamics of tourism development in the South Bohemia Region. The subject of the model is then represented by the researchers (authors) as the observers/descriptors of the model. The SFD represents a mathematical simulation model. Figure 1 shows the SFD structure.

The compiled model of the tourism destination system includes 14 stock variables that form the base of the model. Each stock variable has its own inflow(s) and usually, but not necessarily, outflow(s). Stocks represent accumulations within a system and flows increase (inflows) or decrease (outflows) stocks. Auxiliary variables and stocks control the flows. Therefore, a stock can be changed only via its flows, and stocks and auxiliary variables control the flows (Mai \& Smith, 2018). Constants are used for setting the policies and scenarios simulations. Figure 2 shows a part of the SFD focusing on accommodation capacity where the Accommodation establishments (AE) capacity variable represents the stock, Investments the inflow, $A E$ closing and Depreciation the outflows, $A E$ occupancy and $A E$ building necessity the auxiliary variables, and $A d$ ditional investments the constant.

In this study, we focus primarily on the variables linked to the entrepreneurs' performance, such as Profit\&Loss, accommodation capacity, or number of days spent by visitors in the destination. However, the model enables us to set the policies and simulate scenarios in a sustainable manner because it includes also the variables related to public administration (e.g. tax revenues), residents' attitudes (residents irritation), and the environment (cultural and natural potential). The model structure is described in Appendix 1.

\section{Model Calibration and Validation}

After the SFD structure construction, the model must be calibrated with parameter values to run the simula- 


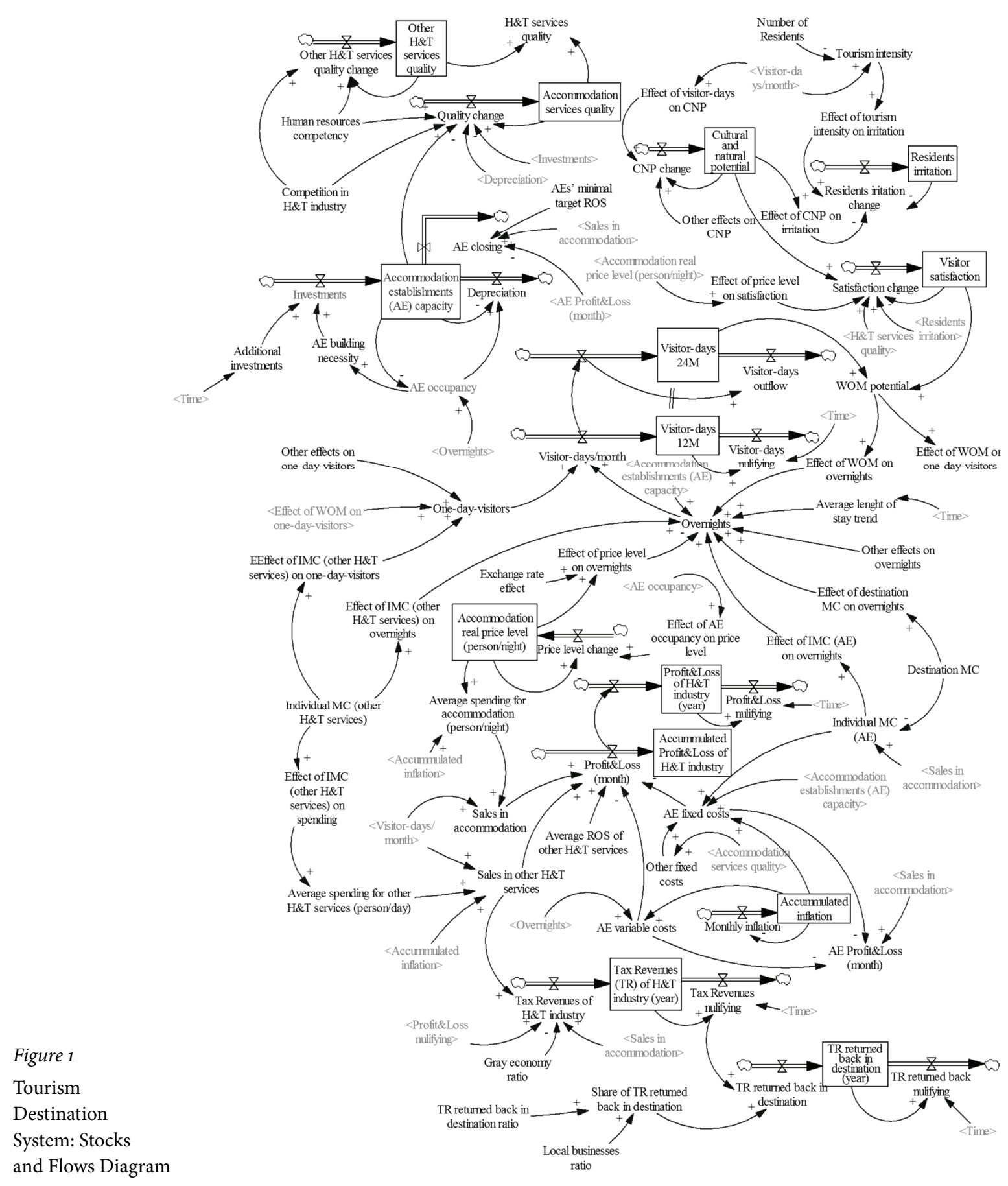

tions. These parameters include (a) the initial value for stocks at the beginning of the simulation, (b) constants that are stored as auxiliary variables, and (c) graphical functions that represent the influence of one variable on another. The remainder of the SFD is parametrised using equations (Mai \& Smith, 2018; Sterman, 2000). The time step of the simulation is one month, and the simulations run for 120 time-steps (10 years). 


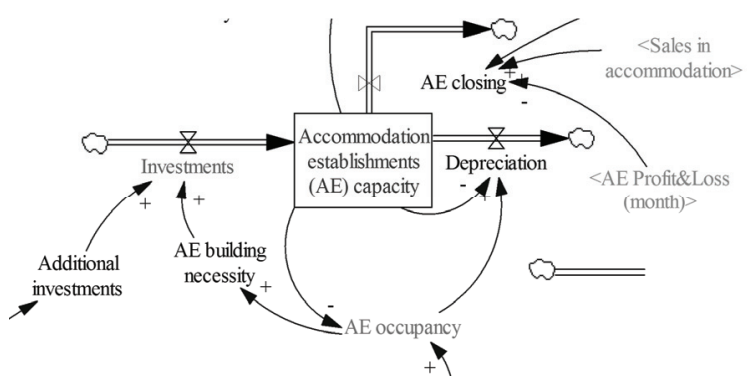

Figure 2 Stocks and Flows Diagram: Accommodation Capacity

A wide set of secondary data about the numbers of destination visitors, length of stay, and accommodation capacity was collected to calibrate the simulation model. The base year for these statistics was 2019 . Some variables, such as the price level, indications of quality, satisfaction, or residents' irritation, were estimated based on consultations with professionals from the region.

Calibration of the simulation model, as well as the initial values, equations and data sources are shown in the supplementary file generated by Vensim 6 Professional (https://fm.vse.cz/english/sfd-irritation2).

We validated the simulation model to achieve the real-life behaviour of the system. The behaviour of the model was compared with the situation after the first COVID-19 wave in the Czech Republic (March-May 2020) and the post-wave behaviour of the system. We followed the results of own research studies and used primary data focusing on the effects of the Covid19 pandemic on SMES in the Czech Republic, or visitor profiles and satisfaction in South Bohemia. Moreover, we used a range of studies about the CoviD-19 impacts on the hospitality and tourism industry published by the Unw TO and the Czech Tourism Board (https://www.unwto.org and https://tourdata.cz /temata/data/).

\section{Results}

We simulated three possible scenarios (Scenario o, Scenario 1, and Scenario 2) of future tourism development in connection with the hospitality and tourism industry restart in the post-CoviD-19 period. These three possible future scenarios are confronted with the theoretical situation without the COVID-19 disease. Using Vensim 6 Professional software, we utilise the SyntheSim function for scenarios simulations.

\section{Scenario without the covid-19 Disease}

In this scenario, we simulate the theoretical situation of how the hospitality and tourism industry in South Bohemia would be developing if the CoviD-19 pandemic had not occurred. The development would be natural and continuous without any external impacts and specific politics.

\section{Scenario o}

We consider Scenario o as the base situation when we consider the basic impacts of the COVID-19 pandemic. We changed the input parameters as follows:

- $43 \%$ decrease of the Number of visitor days based on the statistics (https://tourdata.cz/temata/data/).

- The Human resources competency index decreased from 0.5 to 0.4 because of the professionals and employees outflow from the hospitality and tourism industry.

- The Competition in the hospitality \& tourism industry index decreased from 0.8 to 0.6 due to the closing of businesses as a result of the COVID-19 pandemic restrictions.

\section{Scenario 1}

Scenario 1 is considered as a pessimistic situation when people will be generally scared to travel. In comparison with the base situation (Scenario o), we consider 30\% fewer overnights and one-day-visitors in Scenario 1.

\section{Scenario 2}

Scenario 2 is considered as an optimistic situation when people will be generally anxious to travel since they were not able to go on holidays during the covid19 pandemic. In comparison with the base situation (Scenario o), we consider 30\% more overnights and one-day-visitors in Scenario 1.

\section{Simulations Results}

The simulation results show that the number of visitors and days spent in South Bohemia after the tourism 


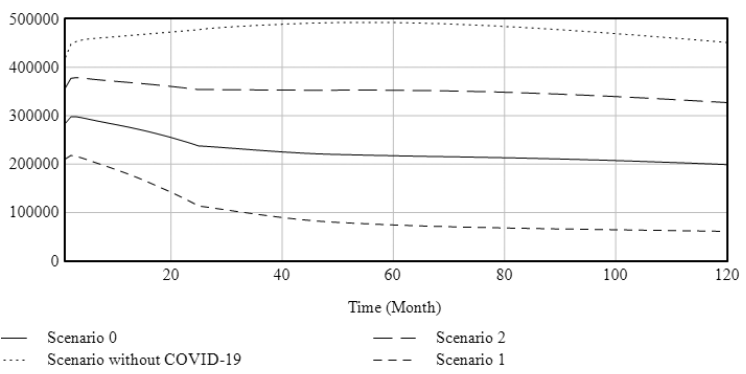

Figure 3 Scenario Simulations: Number of Visitor-Days

restart could drop quite dramatically (Figure 3). If we consider the optimistic Scenario 2, the number of visitor-days will be $72 \%$ of the situation without Covid-19 at the end of the simulation (step 120). However, if we consider the base situation (Scenario o) and the pessimistic Scenario 1, the number of visitor days will be $44 \%$ of the situation without Covid-19 (Scenario o), or 13\% respectively (Scenario 1), at the end of the simulation (step 120).

From the simulation results, we can analyse the situation in the hospitality and tourism industry. The simulation shows how Profit\&Loss develops in particular situations. While the accommodation industry will achieve profits only in the optimistic Scenario 2 at the end of the simulation period (Figure 4), the other hospitality and tourism services will be profitable in the optimistic, as well as in the base, situation at the end of the simulation (Figure 5).

Figure 6 shows the development of accommodation establishments occupancy. The results show that the stabilisation of the accommodation sector will last significantly longer in pessimistic Scenario 1.

The simulated scenarios showed a possible development of the hospitality and tourism industry in the South Bohemia Region, the Czech Republic. The simulation shows that the recovery after the tourism restart will not be easy, and the hospitality and tourism industry will suffer from several related problems, such as the outflow of human resources from the $\mathrm{H} \& \mathrm{~T}$ sector.

\section{Discussion and Conclusion}

A tourism destination is considered to be a dynamic complex system. Managing tourism destinations is

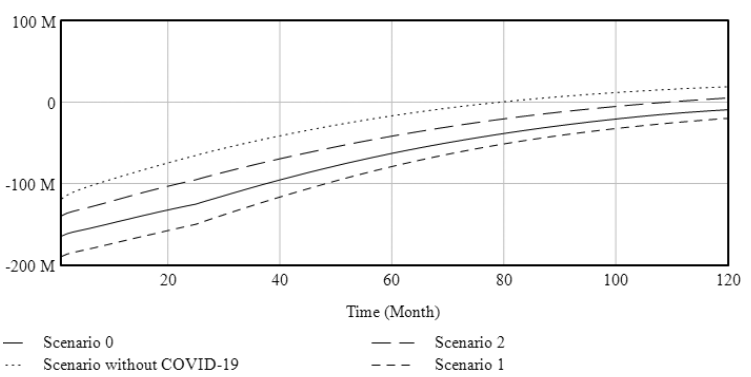

Figure 4 Scenario Simulations: Accommodation Establishments Profit\&Loss

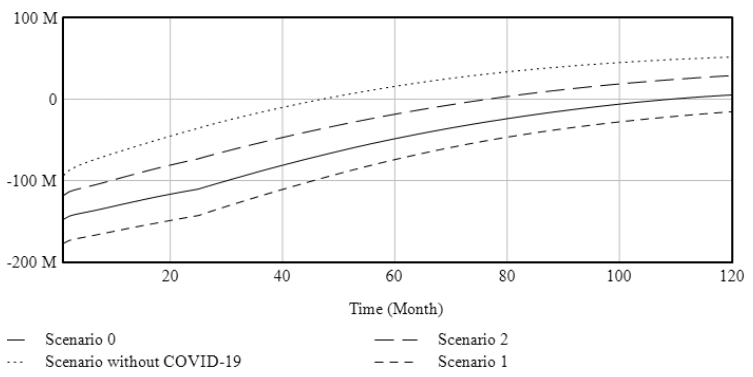

Figure 5 Scenario Simulations: Other H\&T services Profit\&Loss

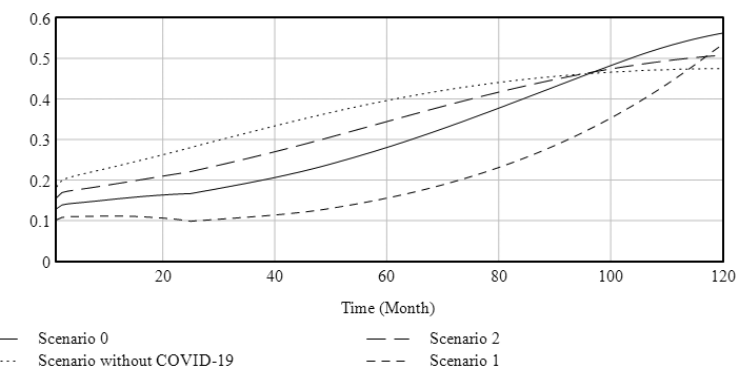

Figure 6 Scenario Simulations: Accommodation Establishments Occupancy

uncertain, and destination managers have to make decisions in a complex environment, including many stakeholders with different management objectives and interests (Mai \& Smith, 2018). System dynamics in travel and tourism research was used by many researchers (Borštnar et al., 2011; Jere Jakulin, 2016; 2017; Jere Lazanski \& Kljajic, 2006; Mai \& Smith, 2018; Patterson et al., 2004; Ropret et al., 2014; Sedarati et al., 2019; Štumpf \& Vojtko, 2016; Tan at al., 2017; Tegegne et al., 2018; Vojtko and Volfová, 2015). Our study iden- 
tifies the complexity of the destination system using a Stocks and Flows Diagram and simulation modelling. Moreover, we use the model for scenarios simulations in the COVID-19 tourism crisis.

The proposed system dynamic model can be considered as a unique tool for destination managers to understand and deal with the soft systems and tourism development policies which determine the dynamics of the destination system. The model enables us to simulate different combinations of possible future development, the effects of decisions and policies, and to test their effectiveness to find the optimal solutions, not only in crisis situations. Therefore, the results can be used practically by destination managers for destination planning and destination strategies formulation.

The theoretical contribution of the model lies in its complexity, and it covers the crucial relations in the destination system respecting the economic, social, and environmental sustainability of tourism. These facts underline the necessity of modelling the destination system properly to achieve efficient destination management (Bieger, 2008; Farrell \& TwiningWard, 2004; Lew \& McKercher, 2006; Rodriguez-Diaz \& Espino-Rodriguez, 2007).

The research question was formulated: How will the hospitality and tourism industry develop in the postCOVID-19 era in the South Bohemia Region? The simulated scenarios show the possible development of the hospitality and tourism industry in the South Bohemia Region, the Czech Republic. The simulation shows that the recovery of tourism will develop differently in various situations, depending on tourist behaviour in the post-Covid-19 era (long-lasting fear of travel, on one hand, and a travel boom, on the other hand). However, the hospitality and tourism industry will suffer from several related problems, such as the closing of tourism businesses, or outflow of human resources from the $\mathrm{H} \& \mathrm{~T}$ sector.

Based on Jere Lazanski and Kljajic (2006), the proposed system dynamic model was established by the authors, as the observers/descriptors of the model. We can consider this fact as a limitation of the study as the model may be influenced, to a certain extent, by the authors' perspective. Other limitations of the model are connected with the calibration. We had to estimate several variables' quantification and their initial values based on experts' opinions. Moreover, it is not easy to set the relations between several variables as graph functions since they usually interact in a non-linear way (Baggio \& Sainaghi, 2011; Mai \& Smith, 2018). Therefore, we were not able to validate the simulation results in their absolute values, but the simulations can point to future development and the differences between various scenarios.

The systems approach and complex system dynamics modelling deserve better attention in future research, in terms of social, environmental, and economic sustainability in tourism destinations. These methods represent the scientific tools that can provide balanced, optimal results to find a consensus among different aims of various stakeholders in tourism destinations. The proposed model can be useful for simulations variety scenarios of the destination system in connection with post-COVID-19 travel behaviour. The precise calibration for the situations in a variety of destinations is the way for future research. This crisis of tourism has shown an enormous and sudden drop in international travel and the reduction of business activities in the hospitality and tourism industry.

The dynamics of tourism and simulations of the post-COVID-19 scenarios represent a big challenge for the future. The current situation outlines the necessity of a complex and systemic approach in managing tourism destinations. Therefore, we consider our system dynamics model a useful tool for decision-making support and sustainable destination development in the post-COVID-19 era.

\section{References}

Ahlert, G. (2008). Estimating the economic impact of an increase in inbound tourism on the German economy using Ts A results. Journal of Travel Research, 47(2), 225234.

Andergassen, R., Candela, G., \& Figini, P. (2013). An economic model for tourism destinations: Product sophistication and price coordination. Tourism Management, $37,86-98$.

Athanasopoulos, G., \& Hyndman, R. J. (2008). Modelling and forecasting Australian domestic tourism. Tourism Management, 29(1), 19-31. 
Baggio, R., \& Sainaghi, R. (2011). Complex and chaotic tourism systems: Towards a quantitative approach. International Journal of Contemporary Hospitality Management, 23(6), 840-861.

Bieger, T. (2008). Management von Destinationen. De Gruyter Oldenbourg.

Bonham, C., Gangnes, B., \& Zhou, T. (2009). Modeling tourism: A fully identified $\mathrm{VECM}$ approach. International Journal of Forecasting, 25(3), 531-549.

Borštnar, M. K., Kljajić, M., Škraba, A., Kofjač, D., \& Rajkovič, V. (2011). The relevance of facilitation in group decision making supported by a simulation model. System Dynamics Review, 27(3), 270-293.

Buchta, C., \& Dolnicar, S. (2003). Learning by simulation: Computer simulations for strategic marketing decision support in tourism. International Journal of Tourism Sciences, 3(1). https://doi.org/10.1080/15980634.2003 .11434540

Farrell, B. H., \& Twining-Ward, L. (2004). Reconceptualizing tourism. Annals of Tourism Research, 31(2), 274-295.

Forrester, J. W. (1961). Industrial dynamics. Productivity Press.

Garson, G. D. (2008). Computerized simulation in the social sciences: A survey and evaluation. Simulation \& Gaming, 40(2), 267-279.

Greiner, R. (2010). Improving the net benefits from tourism for people living in remote Northern Australia. Sustainability, 2(7), 2197-2218.

Jackson, M. C. (2003). Systems thinking: Creative holism for managers. John Wiley \& Sons.

Jere Jakulin, T. (2016). System dynamics models as decisionmaking tools in agritourism. Agricultura, 13(1-2), 5-10.

Jere Jakulin, T. (2017). Systems approach to tourism: A Methodology for defining complex tourism system. Organizacija, 5o(3), 208-215.

Jere Jakulin, T. (2019). Systems approach to cultural tourism and events. Academica Turistica, 12(2), 185-191.

Jere Lazanski, T., \& Kljajic, M. (2006). Systems approach to complex systems modelling with special regards to tourism. Kybernetes, 35(7/8), 1048-1058.

Kaspar, C. (1976). Le tourisme, objet détude scientifique. The Tourist Review, 31(4), 2-5.

Lacitignola, D., Petrosillo, I., Cataldi, M., \& Zurlini, G. (2007). Modelling socio-ecological tourism-based systems for sustainability. Ecological Modelling, 206(1-2), 191-204.

Laesser, C., \& Beritelli, P. (2013). St. Gallen consensus on destination management. Journal of Destination Marketing \& Management, 2(1), 46-49.
Lawson, S. (2006). Computer simulation as a tool for planning and management of visitor use in protected natural areas. Journal of Sustainable Tourism, 14(6), 60o-617.

Lew, A., \& McKercher, B. (2006). Modeling tourist movements. Annals of Tourism Research, 33(2), 403-423.

Liu, C.-H., Tzeng, G.-H., \& Lee, M.-H. (2012). Improving tourism policy implementation - The use of hybrid MCD M models. Tourism Management, 33(2), 413-426.

Mai, T., \& Smith, C. (2018). Scenario-based planning for tourism development using system dynamic modelling: A case study of Cat Ba Island, Vietnam. Tourism Management, 68, 336-354.

Patterson, T., Gulden, T., Cousins, K., \& Kraev, E. (2004). Integrating environmental, social and economic systems: A dynamic model of tourism in Dominica. Ecological Modelling, 175(2), 121-136.

Ritchie, J. R. B. (2003). The competitive destination: A sustainable tourism perspective. СА В I.

Rodriguez-Diaz, M., \& Espino-Rodriguez, T. F. (2007). A model of strategic evaluation of a tourism destination based on internal and relational capabilities. Journal of Travel Research, 46(4), 368-380.

Ropret, M., Jere Jakulin, T., \& Likar, B. (2014). The systems approach to the improvement of innovation in Slovenian tourism. Kybernetes, 43(3/4), 427-444.

Schianetz, K., Kavanagh, L., \& Lockington, D. (2007). The learning tourism destination: The potential of a learning organisation approach for improving the sustainability of tourism destinations. Tourism Management, 28(6), 1485-1496.

Sedarati, P., Santos, S., \& Pintassilgo, P. (2019). System dynamics in tourism planning and development. Tourism Planning \& Development, 16(3), 256-280.

Senge, P. M. (1990). The fifth discipline: The art and practice of the learning organization (1st ed). Doubleday.

Sterman, J. (200o). Business dynamics: Systems thinking and modeling for a complex world. McGraw-Hill Education.

Štumpf, P., \& Vojtko, V. (2016). The system dynamics model for support of the destination management in South Bohemia. Business Trends, 6(4), 43-61.

Tan, W.-J., Yang, C.-F., Château, P.-A., Lee, M.-T., \& Chang, Y.-C. (2018). Integrated coastal-zone management for sustainable tourism using a decision support system based on system dynamics: A case study of Cijin, Kaohsiung, Taiwan. Ocean \& Coastal Management, 153, 131-139.

Tegegne, W. A., Moyle, B. D., \& Becken, S. (2018). A qualitative system dynamics approach to understanding destination image. Journal of Destination Marketing \& Management, 8, 14-22. 
Vojtko, V., \& Volfová, H. (2015). Regional sustainable tourism - A system dynamic perspective. In L. Novacká \& G. Ivankovič (Eds.), Tourism \& hospitality - sustainability and responsibility (pp. 21-40). Profess Consulting.

\section{Appendix 1: Detailed description of the Stocks and Flows Diagram structure}

1. Accommodation establishments (AE) capacity represents one of the key stock variables in the entire model, which is expressed by the number of beds in the destination. The capacity of accommodation establishments (AE) is increased by investments (flow variable; inflow). The total investments in the construction of new accommodation capacities (beds) include either investments due to the need to build capacities (AE building necessity) - to extend the capacity of the existing AEs, or additional investments, in other words, construction of new AES. In this case, the additional investments represent an exogenous variable. In general, however, they may be determined, for example, by the attractiveness of the tourism sector in the destination. It can be increased, for example, by subsidies for the construction of new accommodation capacities. The AE building necessity is given by the occupancy of accommodation facilities, which is expressed as the ratio between the number of overnight stays (per month) and the capacity of accommodation facilities (per month). The total capacity of AES is reduced by two flow variables - a depreciation of accommodation facilities (outflow) and $A E$ closing (outflow). While the depreciation is mainly caused by the occupancy of accommodation facilities (the higher occupancy of the accommodation facility, the higher the wear and tear), the closure of accommodation facilities depends mainly on the monthly financial result of AES and profitability of AES, which in this case is expressed by profitability based on the return of sales (ROS). If the AES do not reach at least the expected AES' minimal target ROS, the accommodation facilities will be closed due to their unprofitability.

2. Accommodation services quality is determined by the change in the quality of accommodation services (quality change, outflow variable), which is influenced by exogenous variables - human resources competency and competition in $\mathrm{H}^{\mathrm{r}} \mathrm{T}$ industry - as in the case of the quality of other services. Furthermore, however, the quality of accommodation facilities is increased by investments placed in accommodation capacities, provided that investments in accommodation facilities exceed their depreciation. The quality of accommodation ser- vices and the quality of other services is then expressed by the auxiliary variable $H^{-} T$ services quality, which influences, together with other factors, the visitors' satisfaction change.

3. Other $H \& T$ services quality is determined by Other $H \& T$ services quality change (flow variable), which in the suggested model is influenced by two exogenous variables - human resources competency and competition in $\mathrm{H}_{\mathrm{H}} \mathrm{T}$ industry. In general, it can be assumed that increase in employees' competencies will increase the quality of, for example, catering, guide, transport, and other services; similarly, the increase in competition should force providers to be more competitive and increase the quality.

4. Accommodation real price level is determined by the price level change (flow variable), which is influenced mainly by the AE occupancy (the effect of AE occupancy on price level). In general, it can be concluded that if the AE occupancy increases, the price of accommodation will also increase. The price level is calculated as the average price per bed/night. For simplification, the price level was calculated only for accommodation services. When summarising other services into one common category, quantifying the price level for all other services would require their detailed elaboration and calculation in a separate model.

5. Accumulated inflation in the proposed model represents a stock variable that needs to be quantified due to the fact that the model considers the real price level for accommodation. The inflow of accumulated inflation is monthly inflation (annual inflation rate calculated for 12 months of the year with respect to the time unit of the simulation, which is one month).

6. Accumulated ProfitઐLoss of $\mathrm{H}_{\mathrm{T}} \mathrm{T}$ industry is stipulated by monthly Profit\&Loss, which represent a flow quantity for the purpose of this model. Financial results of accommodation facilities and the facilities providing other tourism services (to keep the model as simple as possible the other services were not further distinguished) are reflected in a ProfiteLoss (month). Thus, monthly Profit\&Loss is calculated using the difference between revenues from accommodation, and fixed plus variable costs of accommodation facilities and the expected profitability of facilities providing other services. In this case, it is expressed by the average Ros of other H\&T services.

7. Profit\&Loss of H\&T industry (year) had to be quantified not only for monitoring the annual Profit\&Loss in the tourism sector but also for the subsequent quantification of tax revenues from the $\mathrm{H} \& \mathrm{~T}$ industry in the destina- 
tion, which are generated in individual years. The inflow of Profit\&Loss of H\&T industry (year) is also ProfitઐLoss (month) (flow variable). The Profit\&Loss (month) is not accumulated for the whole simulation period as in the previous case, but the Profit\&Loss is nullified after each year. This represents an outflow of Profit\&Loss of $\mathrm{H} \& \mathrm{~T}$ industry (year), and it is possible to derive tax revenue ( TR) of $\mathrm{H} \& \mathrm{~T}$ industry from it.

8. Tax revenues (TR) of $H_{W} T$ industry (year) are in the model (again, with respect to the time unit of the simulation) given by the inflow of tax revenues (TR) of $H \& T$ industry according to individual months (flow variable). For simplification, tax revenues include only income tax and VAT, which are calculated from the total financial result of accommodation and other tourism facilities, in other words, from the revenues from accommodation and other services. Tax revenues are reduced by the assumed grey economy ratio (exogenous variable). Following each year, tax revenues are nullified (flow variable). It is an outflow of annual TRS of the H\&T industry in the destination. It is possible to derive from it in a simplified way the tax revenues returned back in destination (flow variable), which is redistributed and returned to the local and regional budget.

9. TR returned back in destination (year) represent a stock variable that has an inflow in the proposed model in the form of the tax revenues returned back in destination (flow variable) and outflow in the form of $T R$ returned back nullifying in order to determine tax revenues each year. This is the way in which the financial resources are expressed; after the taxes are redistributed the financial resources return to the destination through local and regional public budgets. Their share of the total tax revenues from the tourism sector in the destination will determine the budget allocation of taxes. This fact has been simplified for the purpose of this model to a single coefficient of $T R$ returned back in destination ratio (exogenous variable). Another factor is the Local businesses ratio based in the destination (exogenous variable). Business entities located outside the destination, which provide tourism services in the region, file their tax return at the place of their registered office. This fact reduces the tax revenues that flow back to the destination.

10. Visitor-days per year (Visitor-days $12 \mathrm{M}$ ) is a key stock variable on the demand side. The inflow is (with respect to the time unit of the simulation), for the purposes of this model, expressed in a number of visitordays per month which is given by the sum of overnights and one-day visitors. In the proposed model, the num- ber of one-day visits is influenced by 'word-of-mouth' (effect of шом on one-day visitors), individual marketing communication of other service providers (effect of $I M C /$ ther $H \& T$ services/on one-day visitors), and other effects on one-day visitors (exogenous variable).

The number of overnights can be increased through higher expenditures that the accommodation facilities spend on marketing communication (effect of IMC/A E/on overnights), but also by providers of other services (effect of IMC/other H\&T services/on one-day visitors). A wider offer of other services or higher awareness of the offer can encourage visitors to stay longer. The number of overnights will be further increased by higher expenditures on marketing communication in the destination (Destination $M C$ ), more intensive positive 'wordof-mouth advertising' (effect of WOM on overnights), declining price level (effect of price level on overnights, and related exchange rate effect as an exogenous variable), or other effects on overnights. The number of overnight stays is also influenced by the average length of stay trend (as an exogenous variable), which is based on the global trend of shortening the length of stay of tourism participants in destinations. This fact is due to the preference of tourism participants to travel several times a year for shorter stays. The number of overnight stays is then limited by the capacity of accommodation facilities.

Exogenous variables affecting the number of visitordays (other effects on one-day visitors and other effects on overnights) were used as an input variable for simulation of future development scenarios for the restart of the tourism sector after the COVID-19 era.

11. Visitor-days in the last 24 months (Visitor-days $24 \mathrm{M}$ ) is a stock variable which, in the proposed model, has the same inflow as Visitor-days $12 \mathrm{M}$, and which is the basis for quantifying the wom potential. The proposed model assumes that visitors who have visited the destination in the last 24 months will share their experience with other possible visitors to the destination (their relatives and acquaintances). This means that the visitor-days from the previous 24 months can generate more visitor-days in the future. However, only satisfied visitors will share a positive experience.

12. Visitors' satisfaction is determined by the satisfaction change (flow variable), which in this model is influenced by the $H \& T$ services quality of services, the state of the cultural and natural potential (CNP), the real price level of the accommodation services, and the level of the Residents irritation from tourism. In general, it can be concluded that the satisfaction of visitors will grow in line 
with better cultural and natural potential, in other words with better primary attractiveness of the destination, if the prices decline, but the quality of services grows, and the locals will be more friendly to visitors. The satisfaction of visitors is expressed on the scale in the interval of $[0,1]$. The value of o means that visitors to the destination are completely dissatisfied; in contrast, the value of 1 is assumed in a situation where the visitors would be entirely satisfied with their stay in the destination.

13. Residents' irritation, in the proposed model, is influenced mainly by the tourism intensity, which in this case is expressed by the ratio of the number of visitor days per month to the number of local inhabitants. The second influence that is reflected in the irritation of residents is the cultural and natural potential. The effect of tourism intensity on irritation and the effect of cultural and natural capacity on irritation results in the change in irritation of local inhabitants, which represents a flow variable affecting the current state of the residents' irritation of local inhabitants. In general, in this relation, it can be concluded that the increasing intensity of tourism in the destination increases the irritation of the local population, while the improving cultural and natural environment reduces the irritation of residents. The irritation of local people is expressed on the scale in the interval of $[0,1]$. The value of o means that the local people in the destination are not irritated by the presence of visitors in the destination. In contrast, the value of 1 is assumed in a situation where locals would be upset about the presence of visitors and the negative consequences of tourism as much as possible.
14. Cultural and natural potential (CNP) in the proposed model is mainly influenced by the number of visitordays. In general, it may be concluded that the more days tourists and visitors spend in the destination, the more they will burden the natural environment and affect the local culture, thus degrading the primary capacity of the destination. The effect of visitor-days on CNP and other effects on CNP (exogenous variable) results in the CNP change, which is a flow variable affecting the current state of CNP. Other impacts on the CNP can be investments in historic preservation, environment protection, or generally in improving the attractiveness of the primary capacity of the destination. The model also takes into account a certain degree of self-renewal, especially of the natural capacity of the destination. In this case, favourable conditions for the self-renewal of the destination are assumed, such as an appropriate environmental protection policy or prevention of 'brownfields' creation. CNP is expressed on the scale in the interval of $[0,1]$. The value of o assumes a borderline situation where there would be no natural and cultural capacity in the destination which was creating an attractiveness for tourism. In contrast, the value of 1 is assumed in a situation where the natural and cultural capacity of the destination is at the highest possible level. 